'I'he legumen, or pod, at first, when hanging on the tree, is green and soft, but it soon becomes brown and ligneous; those which grow in India are less hard, and are slender in their form. This tree grows in great perfection in St. Domingo, from which, for a long period, the pods were sent to Spain, and were very much prized ; and Monardes speaks of the tree being planted also in Spain, and yielding a fruit not at all jnferior to that produced in the West Indies. In Egypt the legumes are plucked from the tree before they have arrived at maturity, and placed in houses to which neither light nor heat can have access; they are placed between palm leaves, and for forty days daily sprinkled with water; those are then selected which are not too old, which are not very light, and which have their external covering rough; sometimes the legumes are boiled in water, have sugar added to them, and thus form a sort of preserve which is purgative; but the most usual plan is to forward the legumes to the different ports in their dry state. These are to be bruised, and upon boiling the pulp exudes, which is passed through a sieve, and sugar added until a proper consistence is attained; this is sweetish, and very quickly becomes acid; it should be of a shining bright black colour, and with rather a nauseous odour. Both Vauquelin and Henry have examined into the chemical constitution of this pulp, from which it would appear to consist of a gummy, a glutinous, a saccharine, and a colouring matter, and also of a substance which bears a striking resemblance to tannin.

The electuary, or confection of cassia, is thus made :-Take of fresh cassia pulp half a pound, manna two ounces, tamarind pulp an ounce, syrup of roses eight fluid ounces; bruise the manna, then dissolve it in the syrup; after mix in the cassia and tamarind pulps, evaporate down to a proper consist. ence; half an ounce of this has been sup. posed to be the proper dose, but the laxative power is feeble, and requires the assistnace of the supertartrate of potash, of jalap, or some more powerful remedy to render it really useful. Cullen has great contempt for cassia pulp; but Murray entertains a very favourable opinion of its efficacy for children, for parturient iemales, and for old people; and even speaks of its power in fever of restraining thirst, and correcting the secretions; he also alludes to its employment in calculus, in hysteria, and in melancholia, but in none of these diseases is it employed. The only advantage is in the constipation of people advanced in years, in whom this uncomfortable state arises rather from a rigid state of the fibres of the muscles upon whose action the peristaltic action depends, than from a want of proper biliary secretion. In such cases the cassia senna, either given in its pulp or in the form of confection, is. often found very service- able, neither exciting griping nor heat, but blandly exercising its power over the cand. It should, however, more generally be pre. scrihed in combination, for so large a duse of it alone would overpower the stomach and produce a quantity of flatus. Malouin has made us acquainted with a fact whinh las been borne out by the frequent repetition, that cassia reduces very strikingly the power of the tartar emetic, so that four grains and a half have been given at one dose, without producing severe vomiting of any sort of mischief. When the pulp has been too long kept, it is apt to become raw. cid, and then to be highly deleterious.

The cassia occidentalis, and the cassia Marilandica are species of this family which have been employed medicinally; the latter is officinal, and Barton in the "Veretable Materia Medica of the United States," has given an account of it, and bears testimong to its high character, having employed it in many instances most advantageously as a substitute for Alexandrian senna.

\section{ORGANISATION AND LIFE.}

By J. Johnston Kelso, M.D., Lisbum,

"Life," says Mr. Lawrence, "presup. poses organisation, as the movements of a watch presuppose the wheels, levers, and other mechanism of the instrument." - (Lec. tures on the Physiology, \&c., of Man.) And, conversely, organisation presumes "the ac. tive state of the animal structures," or, in a word-life; as death no sooner takes place than the process of destruction begins. The intimate connection and mutual relationship of the one with the other, which, as an eloquent living writer observes, "is too myste. rious to be explained," is nevertheless $s 0$ evident, and now so generally admitted by all, that it may be correctly considered as a first fact in physiology. Mr. Hunter, there. fore, must be considered in error in asserting that "organisation and life are two different things." Difference there may be in the abstract sense in which these terms are conventionally employed, but, practically viewed, they are assuredly one and insepa. rable.

Premising that organised matter is merely a modification of common matter, through the inexplicable influence of life, organisa. tion is, at least in the sense and langinage of Mr. Hunter, "the compounding of the mater rials of animal matter,--materials the result of combination and arrangement consequent on the previous decomposition of original of inorganic matter. Parts (according to this authority) are first formed from these materials, which on being united, form organs, the junction of a certain number of which, according to certain established rules, are 
asiential to the formation of animals."(Tiorlis, by Palmer.)

But, with all my great admiration for the penetrating genius of this distinguished phssiologist, the definition of organisation Lere given is, I submit, too contracted and refued, embracing only, ns it does, within its meaning, that of the higher orders of animal existence. The idea, too, of Haller, Dr. Willian Hunter, and others, which ascribes organisation to be synonymous with vascularity, is still more objectionable, becallse far mole hypothetical.

Matter, it is almost superfluous here to remark, presents itself to our cognizance mder two aspects only ; either as inorganic brute matter, which forms the vast proportion of the natural objects every where around $u s, 0 r$ as organised living matter. Between these different kinds of matter there is a brad line of demarcation; for the former is especially chnracterised by its homogeneous cumposition, its indeterminate volume, its fat and angular form, its increasing by exterual accretion, and being indefinite as to its duration, from its containing within itself no causes of decay; whilst the latter is no less distinguished by the heterogeneousness of its component elements, and their definite arrangement and organic union, its determinate volume, its rounded or curved form, its increasing by interstitial deposition, and being capable from its very nature of a limited existence only. "And," as is jastly observed by Professor Elliotson, "how deep the chasm between the vital organisation of the meanest vegetable, and a mass of inanimate matter!"- (Human Pilysiology, Part I.)

If all this be admitted to be founded in fact, and there will be none, I think, disposed to dispute its perfect correctness, the science of organisation must evidently be allored a much more comprebensive latitude than that to which it is restricted by those authors to whom I have above alluded, and to be, in point of fact, admitted as coexistent with the very dawn of vital action itself ; for life is organisation in action, or, in the phraseology of Stahl, it is organism.

Organisation may, however, without the inrolvement of any hypothesis, be correctly defined to be the definite arrangement, according to certain established laws, of the ulimate molecules of organic matter, by which certain organic bodies, of a determinate volume, of a structure essentially areolar or cellular, for the circulation of the contained fluids,-characterised by the performance of special phenomena and particular functions, and destined in their nature for a limited existence only-a period of growth, of perfection, and of decay, with the porter of producing all of them their like, are generated. "It is this proper form, this structure common to all living bodies, this areolar tissue, containing fluids more or less abundant, and of the same nature as itself, that is called organisation."-(Beclard.)

Inanimate matter being so changed and recomposed as to have become an organised structure, in addition to those physical properties by which it is characterised in its original simple state, is endowed with others superadded and peculiar to itself, in its then modified condition. These additional properties, which have been designated by the common name of vital, vary remarkably not only in kind, but in degree, in the different phases of the progressive evolution of organised matter, from the simplest of organic structures, the lichen, which struggles through its ephemeral existence, either upon the confines of eternal snow, or upon the regions of the torrid zone (Dr. Sigmond), up to the most perfect and complex of animal existence, as man,-placed, as he is, at the summit of terrestial objects, by the excellence of his mind, and the combination of the common proporties of matter, of those of vegetables, and of those of brites, with those peculiar to himself (Dr. Elliotson); and where Infinite Power, in its wise benificence, bas assigned a period to the vast work of creation, as suited to the physical circumstances of our globe in its existing condition.

In this beantiful law of progressive development, there is manifested marked and in. controvertible evidence of a gradation; each successive order of living creatures, commencing at the lowest, presenting more or less distinct modifications of organisation, and of modes of organic or vital action, by which it is especially distinguished from that of its immediate predecessor in the scale. But does this gradation, founded as it is in nature, deserve the epithet regular or insensible? Philosophers are considerably divided in opinion on this question, but facts, drawn from nature, would seem to wholly overturn the doctrine of Addison, Locke, Dugald Stewart, \&c., respecting the regularity and evenness of this gradation, and go to indicate that it is far from being "regular or insensible."

If, as is ingeniously asserted, "we have reason to believe that life never originates, but began at the creation, and is communicated to assimilated matter, and propagated from parent to offspring,"-(Dr. Elliotson) there is assuredly equally good reason for inferring that organic matter never originates at the period of impregnation, but commenced, like life, from the beginning, and is transmitted, as if, from parent to progeny, from generation to geveration. For, if the assertion of Dr. Elliotson respecting life, be founded in fact, and there are the best grounds for believing that it is so, that which refers to assimilated matter must necessarily be equally so; for life is seen in organised bodies only, and it is in living 
bodies only that organisation is seen."(Beclard).

There are, however, some even of our first physiologists who distinctly deny the universality of this principle of connection and mutual dependance between these, and maintain that the former is not quite peculiar to organised matter, because capable of being possessed by matter in a fluid state. But this is an objection of terms merely,-a refinement in reasoning which runs, $I$ think, fruitlessly counter to a great and pretty widely admitted general principle in physiology.

It may here be inquired are the fluids, which are confessedly vital, as those which are to become the future embryo, and that so styled "queen of fluids," the blood, deroid of all those characteristics essential to organised matter? And, if not so, what are we, then, to consider as their distinctive character? M. Beclard, whose splendid genius shed a rare lustre on most questions of intricacy in physiology, states, as his matured conviction, that the grand distinguishing feature of organised matter consists much more in the circumstance of its arrangement, than in any peculiarity or essential difference in its nature.-(Anatomie Génerale.) Mr. Hunter, too, in reference to the blood, has the following expression, which fairly applies to the other vital fluids. "Blood is not sinply fluid animal matter, it is animal matter particularly arranged, for it differs in every respect from the fluid animal matter produced by art." - $(O p$. Cit. $)$ While, remarks Dr. Bostock, " in its most extensive acceptation, it (organisation) may be regarded as nearly synonymous with the word arrangement." - (Elements of Physiology.) Practical observation, also, of the vital fluids, fully conntenances the fact of a law of arrangement and union of their organic molecules.

True it is that this organic arrangement is not, by any means, to be considered as synonymous with organisation, whether of the physical or physiological kind, any more than the life of a vegetable seed or an ovum, is that of the full-grown plant or animal; but it is the initiatory of that which, by a series of changes and complications, eventuates in the formation of certain structures and organs, performing special phenomena and particular functions, which, in their turn, minister to the preservation of the former. Life, then, in what might not inaptly be called its latent condition, or when devoid of what Mr. Hunter calls "the pouer of action," bears identically the same intimate conuection and relationship to definite. ly arranged fluid matter, as this, in its most complex state, does to the so-called physiological organisation. The former, in fact, cannot be dissociated from the latter, during any period of its limited physical existence, any more than gravitation, or any other pro- perty of matter can, by possibility, be sepa. rated from, and exist independently of that matter itself.

The important question here occurs, is organisation the cause or the effect of the rital principle? This has long been a vigol. ously contested question in physiology, without the almost equally respeciable ad. vocates of the opposite doctrine having as yet come to any definitive arrangement $r e$. specting it ; but the fact is, and it has beell the chief object of this paper all along to eiv. force its correctness, that no priority of $e s$. istence can, in the nature of things, be assigned to either the one or the other; both originate, or rather have originated, coexist, and are annihilated together. More of this, howcver, hereafter.

Lisburn, June, 1838.

\section{TUMOUR IMPEDING DELIVERY.}

\section{To the Editor of THE LANCET.}

SIR :-Perhaps you will have the goodness to give the publicity to the following case, which lately came under ny observation, and which may not be altogether uninterest. ing to the medical readers of your periodical. I am, Sir, yours obediently,

Lower Marsh, Lambeth, July 10, 1838.

J. I. I'o.

I was summoned to attend Mrs. $\mathrm{S}$, in labour with her fourth child, at 12 o'clock, A.M., April 29th, 1837. On instituting an examination per ragina $n, I$ discovered that the cavity of the pelvis was considerably contracted in its antero-posterior diameter, by what $I$ then considered to be a projection of the promontory of the sacrum; the os uteri was too high to admit of $m y$ ascel. taining the character of the presentation. In three hour; after I found that the labour had made considerable progress; the os nteri was dilated to about two-thirds, and the right hand was presenting in front of the vertex. I now discovered that the bony structure of the pelvis was not implicated in the production of the deformity, but that a firm elastic tumour projected from the pro. montory. Having ascertained this, I de. termined on altering the position of the hand, and allowing the vertex to enter the brim in the first position, hoping that the natural uterine efforts might prove sufficient to overcome the resistance. The labour, as might have been anticipated, was of a pro. tracted character, and was terminated by artificial means at seven o'clock in the morning of the 30th. The foetus was turned and brought down by the feet; the secul. dines were soon expelled, and with the ex. ception of consequent exhaustion, the patient felt remarkably well. 